Hans Joachim Marx (Hamburg)

\title{
Zum Gedenken an Günther Massenkeil (1926-2014)
}

Am 17. Dezember des vergangenen Jahres ist Günther Massenkeil nach längerem Leiden in Bad Honnef verstorben. Mit ihm hat die deutsche Musikwissenschaft einen ihrer profiliertesten Vertreter verloren. Am 11. März 1926 in Wiesbaden geboren, wuchs er in einer dem Musischen wie dem Wissenschaftlichen aufgeschlossenen katholischen Familie auf. Nach dem frühen Besuch des Wiesbadener Musikseminars (Klavier und Orgel) vertrat er schon mit 14 Jahren den zum Kriegsdienst eingezogenen Organisten an der St. Kilian-Kirche in Wiesbaden. Im Anschluss an das Abitur am Humanistischen Gymnasium studierte er ein Semester an der Technischen Hochschule in Darmstadt, mit dem vagen Ziel, Orgelbauer zu werden. Trotz einer schweren Erkrankung wurde er noch zwei Monate vor Kriegsende zum Wehrdienst eingezogen, den er aber krankheitsbedingt im Lazarett in Sigmaringen absolvierte. Im Mai 1945 geriet er in französische Gefangenschaft, die er in der Nähe des elsässischen Dorfes Soultz-les-Bains verbrachte. Hier spielte er (unter Bewachung) im Gottesdienst in der Kirche St. Maurice die von Andreas Silbermann erbaute Orgel, deren Restaurierung er später unterstützte. Für dieses Engagement verlieh ihm die Gemeinde von Soults-les-Bains drei Jahre vor seinem Tod die Ehrenbürgerschaft.

Nach seiner Entlassung aus der französischen Internierung studierte Massenkeil von 1947 bis 1951 neben Musikwissenschaft (bei Arnold Schmitz) auch Schulmusik in Mainz. Das Wintersemester 1951/52 verbrachte er mit einem französischen Stipendium an der Sorbonne in Paris. 1952 wurde er mit einer Arbeit über Carissimis lateinische Oratorien in Mainz promoviert, 1961 habilitierte er sich mit einer vieldiskutierten Studie über die Symmetrie in der Instrumentalmusik Mozarts. 1966 zum Professor an der Universität Bonn berufen, entfaltete er eine reiche Tätigkeit als Lehrer und Forscher, aber auch als Sänger und Organisator. Sein wissenschaftliches Hauptanliegen galt den Gattungen der geistlichen Musik, zu denen er bleibende Studien verfasst hat. Eine Auswahl seiner Aufsätze hat er 2008 unter dem Titel Wort und Ton in christlicher Musik veröffentlicht. Als sein populärstes Werk kann das weitverbreitete, auf Marc Honeggers Dictionaire de la musique fußende Große Lexikon der Musik gelten, das bei Herder erschienen ist. Für das 2006 publizierte Handbuch Mozarts Kirchenmusik, Lieder und Chormusik, das er als Mitherausgeber Benedikt XVI. gewidmet hat, ist ihm der Päpstliche Gregoriusorden verliehen worden.

Günther Massenkeil hat sich neben seiner wissenschaftlichen Tätigkeit immer wieder der musikalischen Praxis zugewandt. Als Sänger (Bass-Bariton) hat er in unzähligen Kirchenkonzerten mitgewirkt und hat eigene Liederabende gegeben, die auch auf CD festgehalten sind. Ein Höhepunkt seiner Konzerttätigkeit dürfte der Liederabend gewesen sein, den er 1987 während des Kongresses der IGMW in Bologna im Konservatorium mit Liedern von Musikhistorikern des 19. und 20. Jahrhunderts gegeben hat. Als wissenschaftlicher Organisator hat er jahrzehntelang der Sektion Musikwissenschaft der Görres-Gesellschaft vorgestanden und in deren Auftrag das Kirchenmusikalische Jahrbuch und die Beiträge zur Geschichte der Kirchenmusik herausgegeben. In Anerkennung seiner Verdienste erhielt er 2006 den Ehrenring der Görres-Gesellschaft. Als Motto seines künstlerisch-wissenschaftlichen Lebens wählte er den Ausspruch des Hl. Augustinus „cantare amantis est“, in dem sowohl seine umfassende Liebe zur Musik als auch seine gelebte Katholizität zum Ausdruck kommt. 